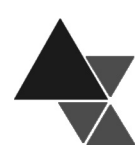

\title{
Fornecimento de alimentos da agricultura familiar para a alimentação escolar: o exemplo do Programa de Aquisição de Alimentos ${ }^{1}$
}

\author{
Panmela Soares $^{2}$, Suellen Secchi Martinelli ${ }^{3}$, Leonardo Melgarejo ${ }^{4}$, Suzi Barletto Cavalli ${ }^{5}$
}

A alimentação escolar vem se transformando em importante mecanismo de escoamento da produção da agricultura familiar. Destaca-se, nesse processo, sua articulação com o Programa de Aquisição de Alimentos (PAA), criado em 2003. Neste artigo, com base em dados coletados em um Município do Estado de Santa Catarina, descreve-se o fornecimento de alimentos pelo PAA para a alimentação escolar, desde o planejamento do projeto de venda até a distribuição dos produtos. Foi realizada uma pesquisa descritiva com abordagem qualitativa, de caráter exploratório, delineada como estudo de caso. Foram realizadas observação direta, análise documental e entrevistas semiestruturadas como técnicas de coleta de dados. Evidenciou-se que a articulação entre os agentes locais foi fundamental para o planejamento e execução dos programas, especialmente pela atuação limitada e insipiente da gestão pública municipal e do controle social. O PAA se revelou instrumentalizador de processos de organização e participação social, ampliando a transparência e o controle social de ações públicas. Para o sucesso da articulação entre os diversos setores governamentais e não governamentais envolvidos é necessário, além de apoio eficaz da prefeitura municipal, que todos os agentes disponham de amplo conhecimento sobre as estruturas e da operacionalização dos programas.

Palavras-chave: agricultura familiar, alimentação escolar, políticas públicas, Segurança Alimentar e Nutricional.

\section{The food supply of the family farming to school feeding: the example of the food Acquisition Program}

The school feeding is becoming an important mechanism to flow the products of the family farming. It is remarkable, in this process, its relationship with the food Acquisition Program (PAA), created in 2003. In this article, based on data collated in a municipality of the State of Santa Catarina, describes the food supply by PAA to school feeding. The working strategy adopted was descriptive research with qualitative approach, with an exploratory character, outlined as a case study. The techniques used were direct observation, document analysis and semi-structured interviews. It was evident that the articulation of local agents (in this case it is happened through farmers' cooperative) is essential for planning and implementing of the program, particularly when (as in the case) the participation of municipal public management and social control are shown incipient and limited.

\footnotetext{
1 O presente artigo é fruto da dissertação de mestrado de Panmela Soares, intitulada "Análise do Programa de Aquisição de Alimentos na alimentação escolar em um Município de Santa Catarina”. Programa de Pós-graduação em Nutrição, Departamento de Nutrição, Núcleo de Pesquisa de Nutrição em Produção de Refeições, Universidade Federal de Santa Catarina (UFSC), 2011.

${ }^{2}$ Mestre em Nutrição pelo Programa de Pós-Graduação em Nutrição, Núcleo de Pesquisa de Nutrição em Produção de Refeições, UFSC. Nutricionista da Secretaria Municipal de Saúde de Itajaí, Departamento de Atenção à Saúde. Correspondência: Campus Universitário, Trindade, Florianópolis, SC. CEP 88040-900.E-mail: panmela_soares@yahoo.com.br.

${ }^{3}$ Mestre em Nutrição pelo Programa de Pós-Graduação em Nutrição, Núcleo de Pesquisa de Nutrição em Produção de Refeições, UFSC.

${ }^{4}$ Doutor em Engenharia de Produção, UFSC. Instituto Nacional de Colonização e Reforma Agrária (INCA), Brasil.

${ }_{5}^{5}$ Doutora em Alimentos e Nutrição, Universidade Estadual de Campinas (UNICAMP). UFSC, Centro de Ciências da Saúde, Departamento de Nutrição, Florianópolis, SC.
} 
However the PAA allows processes of organization and social participation, increasing the transparency and social control of public actions. The study results point to the operational complicity of the program and to the need for integration between the agents involved. For successful coordination between the several governmental and non-governmental sectors involved in the PAE and the PAA is necessary, as well as strong support from municipality, that all agents possess extensive knowledge about the structures and the operation of the programs.

Key-words: family farm, school feeding, public policies, Food and Nutrition Security.

\section{INTRODUÇÃO}

A atual legislação do Programa Nacional de Alimentação Escolar (PNAE) vem transformando as escolas da rede pública de ensino em importante mecanismo de escoamento da produção da agricultura familiar ${ }^{[1]}$. Esse processo se faz especialmente relevante a partir de 2003, com a criação do Programa de Aquisição de Alimentos (PAA). O Programa tem o objetivo de garantir, a populações em situação de Insegurança Alimentar e Nutricional, o acesso a alimentos em quantidade, qualidade e regularidade necessárias; promover a inclusão social no campo por meio do fortalecimento da agricultura familiar; promover o abastecimento institucional com alimentos para diversos fins, como a alimentação escolar; e constituir estoques estratégicos [2].

Diferentemente da aquisição de alimentos da agricultura familiar com recursos do Fundo Nacional de Desenvolvimento da Educação (FNDE) [1], o abastecimento do PNAE com alimentos do PAA não é obrigatório. Entretanto, pode ocorrer mediante a elaboração de projetos em âmbito municipal. Em tal circunstância, são adquiridos para doação simultânea, com recurso do Ministério do Desenvolvimento Social e Combate à Fome (MDS). A relevância da referida modalidade no âmbito do PAA pode ser evidenciada na medida em que, do total de recurso destinado para a execução do Programa em 2011, 67,9\% foram dedicados para a Compra com Doação Simultânea [3].

Nesse processo, as unidades escolares assumem importante papel como entidades consumidoras dos produtos. Em 2011, as creches e pré-escolas representaram o segmento com maior representatividade $(46,55 \%)$ entre as entidades consumidoras, seguido das associações beneficentes $(11,53 \%)$. Da mesma forma ocorreu no Estado catarinense, onde $37,02 \%$ das entidades atendidas foram categorizadas como creches/pré-escolas, e $16,1 \%$ foram associações beneficentes ${ }^{[3]}$.
Os dados apresentados demonstram a importância das unidades escolares para o escoamento dos produtos da agricultura familiar, necessário para o seu fortalecimento. Nesse sentido, destaca-se que em alguns Municípios a alimentação escolar caracteriza a maior ou ainda a única opção de fornecimento de alimentos do PAA (doação simultânea). É oportuno comentar a relevância desse fornecimento também para a qualidade da alimentação escolar, ampliando a oferta de alimentos, em especial em Municípios com menor disponibilidade financeira.

Destaca-se que os referidos produtos visam complementar o abastecimento de escolas, que já recebem alimentos adquiridos com recursos do FNDE, repassados especificamente para esse fim. Como a dinâmica entre os programas é complexa, apresenta-se na Figura um esquema da articulação financeira da alimentação escolar com o PAA.

A execução do PAA vem sendo relacionada ao fortalecimento da agricultura familiar. Estudo realizado por Becker \& Sacco dos Anjos [4] confirma sua importância para a inclusão social no campo e valorização dos produtores locais. Os impactos do Programa sobre o aumento, a diversificação e a qualificação da produção são evidenciados em Delgado et al. ${ }^{[5]}$ e Becker \& Sacco dos Anjos [4]. Segundo Müller et al. [6], o PAA também tem auxiliado os agricultores a ampliar seu acesso a novos mercados.

Avaliando a repercussão do Programa sobre entidades consumidoras, Zimmermann \& Ferreira [7], Vieira \& Del Grossi ${ }^{[8]}$ e Becker \& Sacco dos Anjos [4] apontaram melhorias na qualidade da alimentação servida e aumento na ingestão de frutas, hortaliças e carnes.

De uma maneira geral, é possível afirmar que o fornecimento de alimentos da agricultura familiar para a alimentação escolar apresenta benefícios para consumidores e produtores. De um lado, observa-se a 
Figura. Articulação do Programa Nacional de Alimentação Escolar (PNAE) com o Programa de Aquisição de Alimentos (PAA)

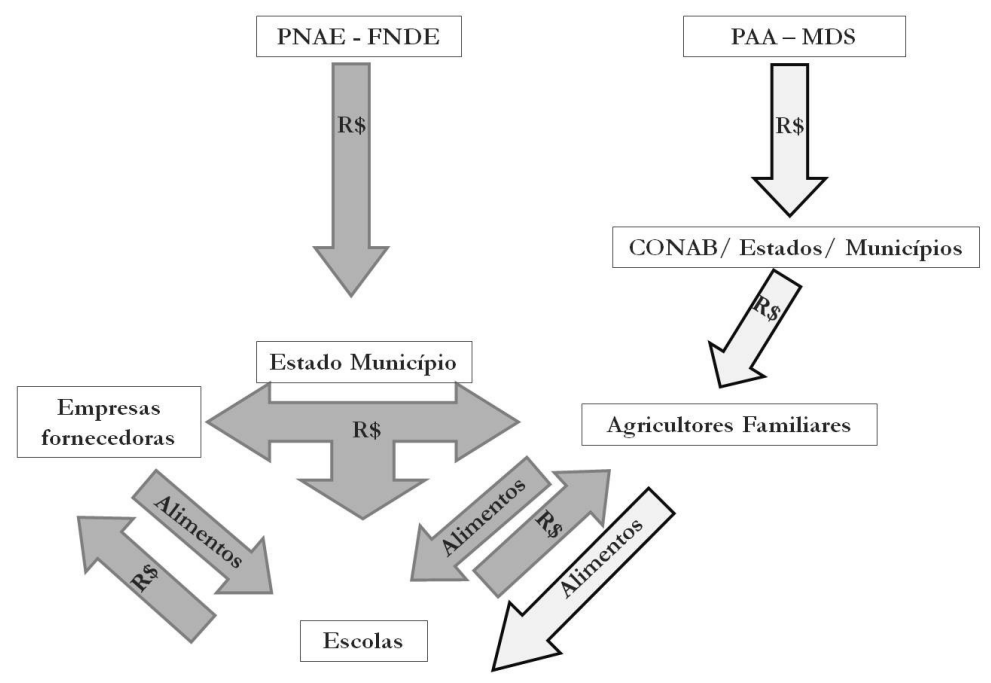

Fonte: Elaborado pelos autores.

melhoria da qualidade da alimentação escolar [9,10], de outro, o fortalecimento das atividades produtivas familiares $[9,11,12]$.

No entanto, uma das limitações indicadas pelos produtores e consumidores para a implantação do PAA diz respeito à falta de clareza quanto aos procedimentos, às modalidades e aos objetivos do Programa $[9,11,13]$.

A ampliação dos benefícios gerados pelo fornecimento de alimentos da agricultura familiar para a alimentação escolar exige que os envolvidos no planejamento e operacionalização dos programas conheçam em detalhe suas especificidades e possíveis formas de execução. Tendo em vista contribuir nesse sentido, e com base em situações identificadas em campo, o presente artigo oferece elementos que podem auxiliar gestores municipais ao qualificarem o processo de fornecimento de alimentos do PAA, para a alimentação escolar em seus Municípios. Para tanto, descreve-se o processo de fornecimento de alimentos pelo PAA para a alimentação escolar em um Município do Estado de Santa Catarina, desde o planejamento do projeto de venda até a distribuição dos produtos, enfatizando aspectos com maior potencial de representatividade e generalização.

\section{METODOLOGIA}

Como estratégia adotou-se a pesquisa descritiva com abordagem qualitativa, de caráter exploratório, delineada como um estudo de caso. A escolha do local da investigação foi realizada entre os Municípios do Estado de Santa Catarina em que o PAA estava fornecendo alimentos para a alimentação escolar, com base em determinados critérios: possuir responsável técnico-nutricionista; tempo de execução do PAA e aceitar participar da pesquisa. Salienta-se a necessidade da presença do nutricionista para a seleção do Município, diante de sua relevância no processo do planejamento e execução do PNAE, desde o planejamento do cardápio até o processo de aquisição e recebimento dos alimentos.

A coleta de dados foi realizada em setembro de 2010. As técnicas utilizadas foram: entrevistas semiestruturadas, observação direta e análise documental. Durante as entrevistas, os entrevistados discorreram sobre as questões apresentadas, revelando detalhes fundamentais do processo de fornecimento de alimentos do PAA para a alimentação escolar, auxiliando na compreensão do fenômeno estudado. 
Participaram das entrevistas Gestores e Funcionários da alimentação escolar (um Representante do Conselho de Alimentação Escolar (CAE), dois Nutricionistas da alimentação escolar, um Secretário da Educação e três Cozinheiras); Gestores e Funcionários da agricultura (um Extencionista rural, um Engenheiro Agrônomo, dois Técnicos Agrícolas, um Secretário da Agricultura); e representantes da organização dos agricultores (três Agricultores Familiares, um Representante da Cooperativa de agricultores).

As entrevistas foram realizadas com base em um roteiro norteador diferenciado para os segmentos entrevistados. As questões contemplaram itens sobre planejamento e elaboração do projeto de vendas e distribuição dos produtos.

As entrevistas foram gravadas com $O$ consentimento dos entrevistados, sendo transcritas posteriormente. $\mathrm{O}$ tempo das entrevistas variou de 16 minutos a $2 \mathrm{~h} 20 \mathrm{~min}$, de acordo com o agente entrevistado, totalizando $10 \mathrm{~h} 51 \mathrm{~min} 23 \mathrm{~s}$.
Outra técnica utilizada foi a observação, que permite obter informações no momento em que o fato ocorre. Foram acompanhadas entregas no depósito central da alimentação escolar e em duas escolas municipais. A observação foi realizada também em visitas a propriedades de agricultores fornecedores de vegetais e frutas para alimentação escolar e às unidades de ensino. A observação permitiu uma maior compreensão do processo de distribuição, transporte, recebimento e armazenamento dos produtos.

A análise documental objetivou identificar questões como número de agricultores envolvidos, entidades consumidoras e produtos fornecidos. Para isso, foram analisados os documentos disponibilizados pela organização dos agricultores, possibilitando o acesso a informações do planejamento e execução do Programa. Os documentos analisados foram: projeto de venda do PAA de 2009 a 2010; e listagem dos produtos do projeto de venda do PAA de 2007, ano de início do PAA no Município. O Quadro apresenta as variáveis e dimensões pesquisadas, assim como as técnicas de coleta de dados utilizadas para cada variável.

Quadro. Variáveis, dimensões e técnicas para coleta de dados

\begin{tabular}{|l|l|l|}
\hline \multicolumn{1}{|c|}{ Variável } & Dimensão & \multicolumn{1}{|c|}{ Técnicas para a coleta de dados } \\
\hline Política de abastecimento & $\begin{array}{l}\text { Elaboração do } \\
\text { projeto de venda } \\
\text { Entrevista com gestores e funcionários da alimentação } \\
\text { escolar; gestores e funcionários da agricultura; representantes } \\
\text { da organização dos agricultores. }\end{array}$ \\
\hline $\begin{array}{l}\text { Entrega/Recebimento dos } \\
\text { produtos nas unidades de } \\
\text { produção de refeições } \\
\text { escolares documental (Projeto de Venda para o Programa de } \\
\text { Aquisição de Alimentos) }\end{array}$ & Transporte & $\begin{array}{l}\text { Observação direta no recebimento do produto. } \\
\text { Entrevista com gestores e funcionários da alimentação } \\
\text { escolar; gestores e funcionários da agricultura; representantes } \\
\text { da organização dos agricultores. }\end{array}$ \\
\hline
\end{tabular}

Fonte: Elaborado pelos autores.

Após a coleta, os dados foram registrados e analisados com base em variáveis referentes à política de abastecimento e recebimento dos produtos nas unidades escolares. Para a análise das entrevistas e dos documentos, foi realizada a transcrição, com posterior leitura do material, com o intuito de compreender o processo estudado. Posteriormente, foi realizada a codificação das informações, agrupando os dados de forma a realizar a descrição das características relevantes, respeitando os critérios de objetividade, sistematização e generalização [14]. Os dados provenientes da observação complementaram as informações coletadas durante as entrevistas.

A pesquisa foi aprovada pelo Comitê de Ética em Pesquisa com Seres Humanos (CEPSH), da 
Universidade Federal de Santa Catarina (UFSC), sob o protocolo 914/2010.

\section{RESULTADOS E DISCUSSÃO}

\section{Caracterização do local de estudo}

O estudo foi realizado em um Município situado no planalto Norte do Estado de Santa Catarina, onde desde 2007 a rede municipal de ensino recebe do PAA - produtos da agricultura familiar para a alimentação escolar. O projeto foi elaborado pela Cooperativa dos Agricultores e contou com a participação de 32 agricultores, como fornecedores de vinte entidades consumidoras.

Em 2010 a alimentação escolar municipal atendeu 6.397 alunos regularmente matriculados na educação infantil, ensino fundamental e Ensino de Jovens e Adultos (EJA). Para isso, a região dispunha de 34 unidades de ensino e três profissionais nutricionistas atuando junto à alimentação escolar.

A legislação do PNAE referenda a relevância do profissional nutricionista como responsável técnico do Programa. Entre as atribuições estabelecidas pelas regulamentações, o profissional deve planejar os cardápios escolares, acompanhando desde a aquisição dos alimentos até a distribuição das refeições ${ }^{[15] .}$

Cabe salientar que as entidades executoras do PNAE devem cumprir os parâmetros numéricos mínimos de referência de nutricionistas por escolares, previstos em normativa específica do Conselho Federal

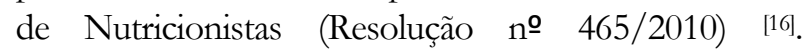
Contudo, registra-se que o Município possui número inadequado de nutricionistas atuando no Programa, contrariando as normas regulamentares vigentes. A insuficiência na quantidade de profissionais pode dificultar o cumprimento de suas atribuições, interferindo no planejamento e execução do Programa.

A fim de suprir as necessidades das unidades de ensino, os alimentos eram adquiridos por diversas vias. Em 2010 foram realizadas três licitações e três chamadas públicas para aquisição de alimentos, além dos produtos fornecidos pelo PAA. A aquisição dos produtos armazenados em temperatura ambiente, das carnes, de parte das frutas e dos vegetais, foi realizada por licitação. Por chamada pública de compra, foram adquiridos vegetais e frutas da agricultura familiar.
Pelo PAA podem ser adquiridos produtos in

natura; $\quad$ produtos industrializados/processados/beneficiados; e produtos orgânicos [17]. No caso estudado, evidenciou-se que o PAA foi responsável pelo fornecimento de vegetais, frutas, leguminosas e alguns alimentos processados, como pães e geleias.

\section{Operacionalização do Programa de Aquisição de Alimentos (PAA)}

O PAA é executado pelas prefeituras, governos estaduais e pela Companhia Nacional de Abastecimento (CONAB), em parceria com o Ministério do Desenvolvimento Agrário (MDA) e com o Ministério do Desenvolvimento Social e Combate à Fome (MDS), responsáveis pelos recursos financeiros para a execução do Programa [8]. Visando à implementação do PAA, o MDS e o MDA podem firmar convênios com os órgãos ou entidades da administração pública estadual, distrital ou municipal, direta ou indireta, para que dele participem, inclusive com aportes financeiros ${ }^{[18]}$.

O Programa pode ser executado em diferentes modalidades: compra direta da agricultura familiar para distribuição de alimentos ou formação de estoque público; apoio à formação de estoque pela agricultura familiar; compra da agricultura familiar com doação simultânea; compra direta local da agricultura familiar com doação simultânea; incentivo à produção e ao consumo do leite; aquisição de alimentos para atendimento da alimentação escolar [18].

No período de coleta de dados, as escolas municipais estavam recebendo alimentos provenientes do PAA adquiridos pela modalidade de Compra para Doação Simultânea (apoiada pelo MDS).

Nessa modalidade, a Cooperativa ou a associação de agricultores familiares vendem seus produtos para o governo, por meio da CONAB. Os produtos adquiridos são entregues diretamente aos consumidores. Nesse caso, os consumidores podem ser formados por equipamentos públicos de alimentação e nutrição (Restaurantes Populares, Cozinhas Comunitárias, Unidades de Apoio à Distribuição de Alimentos da Agricultura Familiar, Bancos de Alimentos e Mercados Populares), ou redes socioassistenciais, governamentais ou não governamentais, que atendam populações em situação de Insegurança Alimentar e Nutricional [17]. 
Para participar do fornecimento de alimentos por meio do PAA, a organização dos agricultores precisa realizar um plano de trabalho e apresentar uma proposta de participação [19]. Esse comprometimento dos agricultores se mostra benéfico para todos os envolvidos; alguns estudos, inclusive, apontam a importância do envolvimento dos atores sociais, por intermédio de suas organizações, para o planejamento e a execução bem sucedida do PAA [6,20]. Müller et al. [6] referem correlação positiva entre os resultados do Programa e o grau de envolvimento de associações, Cooperativas e organizações não governamentais.

No Município estudado, a Cooperativa dos Agricultores Familiares assumiu a responsabilidade de organizar a produção e manifestou interesse em comercializar via PAA, elegendo as unidades escolares como consumidoras dos produtos. Nesse momento, não foi observada a participação dos nutricionistas responsáveis pela alimentação escolar do Município.

Cabe salientar que, para o fornecimento dos alimentos para escolas públicas, exige-se que a autoridade competente pela gestão dos recursos recebidos do FNDE declare que os aplicará integralmente na alimentação escolar, agregando, ademais, sua parcela de contrapartida. Além disso, são necessários o parecer do Conselho de Alimentação Escolar (CAE) e a justificativa da necessidade de complementação alimentar pelo PAA [17].

O Programa conta ainda com o controle social por intermédio da participação dos Conselhos de Segurança Alimentar e Nutricional (CONSEAs) ou de outros conselhos semelhantes, atribuindo, desse modo, alta confiabilidade ao processo na sua totalidade [8,21]. Triches \& Schneider [12] apontam as reuniões dos conselhos municipais como importantes espaços de trocas e negociação. Talvez em vista de tais características, observa-se que a desarticulação ou mesmo a fragilidade do controle social representam dificuldades para a execução do PAA [11,13, 20,22]. Estudo realizado por Doretto \& Michellon [11] concluiu que a maioria dos agricultores desconhecia a existência e as atribuições do Conselho Municipal responsável pelo acompanhamento do Programa.

No caso estudado também se evidenciou a não participação do Conselho de Alimentação Escolar na elaboração do projeto do PAA. A atuação do CAE estava limitada à fiscalização dos recursos e execução do PNAE nas escolas municipais. O envolvimento maior com o PAA ocorria por intermédio do Conselho Municipal de Segurança Alimentar e Nutricional (COMSEA), em que pese sua participação ocorrer de forma incipiente. Salienta-se que o COMSEA foi constituído exatamente em razão da necessidade de controle social, conforme estabelecido pelas normativas do PAA. Na ocasião da elaboração do projeto de venda por meio do PAA, pela Cooperativa, sua proposta foi avaliada e aprovada pelo referido conselho.

Sparovek et al. [22] igualmente fazem referência à importância do controle social do Programa, mencionando que, com frequência, suas ações tendem a se limitar ao cumprimento de exigências burocráticas. Nesse aspecto, salienta-se que a estruturação de processos de controle social pode auxiliar na identificação e correção de distorções que reduzem a eficácia do Programa, contribuindo, ainda, para expandir a qualidade e a quantidade de produtos comercializados ${ }^{[9]}$.

Triches \& Schneider [12] mencionam tais aspectos chamando a atenção para a necessidade da construção de diálogo entre os atores envolvidos no processo de aquisição de alimentos da agricultura familiar, voltados ao atendimento da alimentação escolar.

No entanto, essa não é a situação mais frequente, como se percebe em estudo realizado por Vieira \& Del Grossi [8], acusando ausência de participação das entidades consumidoras nas decisões sobre a quantidade e regularidade de entrega dos produtos.

No caso estudado isto se repete: as escolas, a Secretaria de Educação e os nutricionistas não participaram efetivamente da elaboração do projeto. Este havia sido elaborado pela Cooperativa, que apresentou uma proposta acabada para a apreciação da Secretaria de Educação. No que se relaciona à participação de representantes governamentais, a elaboração e a execução do projeto contaram apenas com o apoio dos órgãos da gestão da agricultura, para divulgação do Programa aos agricultores e assistência técnica. Em outras palavras, o escasso apoio do poder público local também se caracteriza como uma das dificuldades do PAA [13].

Assim sendo, salienta-se o necessário envolvimento e a ação articulada dos diversos agentes, cobrindo a intersetorialidade, que media desde a 
agricultura familiar até a alimentação escolar. Nesse processo, cabe destacar a relevância da participação do profissional nutricionista, diante de sua centralidade no planejamento e execução do PNAE. Nesse contexto, torna-se indispensável o planejamento e a operacionalização conjunta dos cardápios com a produção agrícola, visando à garantia da qualidade da alimentação escolar, bem como a estruturação da agricultura familiar.

Tendo em vista a organização dos agricultores para a elaboração do projeto, a Cooperativa realizou reuniões nas diversas comunidades. Nas ocasiões, houve divulgação do Programa e foram mapeados os agricultores interessados em comercializar seus produtos. Salienta-se a importância de iniciativas como essa, que contribuem para a divulgação do Programa, tendo em vista que a falta de informações tem sido apontada como uma de suas maiores dificuldades [9,13]. A esse respeito, ressalta-se estudo realizado em três Municípios paranaenses em 2005 o qual apontou que os agricultores consideraram inexistente a divulgação do Programa [11].

Como já referido, cabe à entidade proponente do projeto elaborar sua proposta de participação, que deve conter informações sobre os produtores, produtos e consumidores. $\mathrm{O}$ nível de detalhamento prevê especificação das quantidades produzidas, período de entrega, entidades consumidoras, número de pessoas atendidas em cada entidade, produtos e quantidades a serem entregues em cada unidade, entre outras informações [8,17].

Para a elaboração de projeto extremamente detalhado no que tange à entrega de produtos, especificando suas quantidades e qualidades ao longo do tempo, a Cooperativa de agricultores utilizou como referência uma planilha fornecida pela Secretaria de Educação, elaborada pelos nutricionistas. Essa planilha informava os volumes consumidos por produto, por escola, permitindo orientar programações de coleta/plantio com vistas ao atendimento daquelas demandas. Baseando-se nessa planilha, foi determinado o que cada agricultor produziria, de acordo com suas habilidades e seguindo as orientações da assistência técnica. Nesse momento, foram elaborados os cronogramas de distribuição dos produtos. A planilha de distribuição dos produtos do PAA era repassada semestralmente para as escolas.
Ressalta-se o necessário envolvimento do nutricionista nesse processo, para além do fornecimento de informações da demanda das unidades escolares. A aproximação da produção com o consumo pode auxiliar no processo de elaboração dos cardápios, possibilitando a inclusão de alimentos já produzidos pela agricultura familiar.

O atual limite estabelecido pela CONAB para aquisição de alimentos para doação simultânea é de até $\mathrm{R} \$ 4.800,00$ por participante [17]. No caso estudado, o projeto envolveu 32 agricultores, com um investimento total de $\mathrm{R} \$ 111.975,20$. O valor médio para cada agricultor foi de $\mathrm{R} \$ 3.499,23$. Cabe salientar que os limites de aquisição de alimentos da agricultura familiar para alimentação escolar com recursos do FNDE não possuem vínculo com os valores do PAA [17]. Dessa forma, ao participar de ambos os programas, os agricultores podem elevar sua renda e o volume global de entregas para programas governamentais.

\section{Entrega/Recebimento dos produtos}

Os produtos adquiridos eram entregues para vinte entidades, contemplando um total de 14.919 pessoas atendidas. Das entidades consumidoras, dezenove eram do próprio Município e uma de Município vizinho. Entre as entidades, onze eram escolas municipais (4.368), sete escolas estaduais (3.820), uma Associação de Pais e Amigos do Excepcional (APAE) (273) e um hospital (6.458). Salienta-se que o presente estudo se restringiu ao acompanhamento do PAA das escolas municipais cadastradas como consumidoras.

O cronograma de entrega dos produtos do PAA deve estar contido na proposta de participação [17]. Vieira \& Del Grossi ${ }^{[8]}$ assinalam a falta de exigência do cumprimento de um cronograma de entrega como sendo uma dificuldade do Programa, ressaltando a necessidade de incentivo ao planejamento e ao gerenciamento das atividades.

No caso estudado, os produtos do PAA eram entregues semanalmente. Diante das dificuldades de produção, alterações no cronograma foram relatadas por representantes da Cooperativa e da alimentação escolar. Cordeiro [13] lembra que as perdas ocasionadas por seca ou outras adversidades climáticas comprometem o cumprimento das entregas previstas nos projetos. 
A referida situação aponta para a necessidade de constante diálogo entre os envolvidos, em especial entre nutricionistas e produtores, objetivando a elaboração de critérios de substituição dos produtos que sirvam como referência aos agricultores, minimizando interrupções no fornecimento e modificações nos cardápios escolares. Todavia, no caso analisado, não existiam critérios pré-estabelecidos de substituição de produtos, comprometendo a continuidade das entregas e a execução dos cardápios previamente elaborados nas unidades de ensino.

Segundo regulamentação estabelecida pela CONAB, nos seguintes casos podem ocorrer ajustes das quantidades a serem entregues: necessidade de substituição de produtos originalmente pactuados; resultado de aplicações financeiras; variação da qualidade indicada na classificação dos produtos; alteração de preços dos produtos ${ }^{[17]}$.

Conforme Vieira \& Del Grossi [8], a qualidade dos produtos, a regularidade da oferta e o volume de produção (escala) representam os principais fatores exigidos para o acesso aos mercados. No que se relaciona à agricultura familiar, Lima \& Toledo [23] expandem o leque de dificuldades da agricultura familiar, citando a falta de planejamento, de conhecimento da demanda do consumidor, a baixa escala de produção, assim como a falta de controle da produção.

No Município estudado, o fornecimento de alimentos provenientes do PAA para a alimentação escolar ocorria desde 2007. No início da execução do Programa, as quantidades entregues eram maiores do que a necessidade das escolas, ocasionando sobras. Os prejuízos decorrentes evidenciavam, desde então, a importância e a necessidade do planejamento da produção de forma articulada com a demanda das entidades consumidoras.

Diante da grande oferta, iniciou-se o remanejamento dos produtos, utilizando-se para isso um documento específico (o "termo de remanejamento"), elaborado pela Secretaria de Educação. Diante da inadequação das quantidades, o representante da Cooperativa era informado e deflagrava processo de correção. De uma maneira geral, o pequeno número de envolvidos e a proximidade entre produtor e consumidor possibilitavam a adequação das quantidades a serem entregues, de acordo com o consumo de cada unidade. Resultados semelhantes já haviam sido apontados por Vieira \& Del Grossi [8], em que as quantidades tendiam a ser ajustadas no decorrer da execução do Programa. Destaca-se ainda pesquisa de Zimmermann \& Ferreira [7, mencionando que o PAA auxiliava na organização da forma de produzir, em face das exigências de planejamento da produção e colheita.

De acordo com as regulamentações do Programa, a proposta de participação, da mesma forma, deve apresentar o local onde será realizada a entrega dos produtos [17]. Destaca-se que o transporte dos produtos do local de produção até o de consumo caracteriza-se como mais uma importante dificuldade para a execução do Programa [7-9,13, 20]. Basicamente, as grandes distâncias, as precárias condições das estradas, a falta de veículos e o elevado custo acabam por limitar a participação e execução do PAA [9]. Nesse sentido, Cordeiro [13] recomenda que, desde a elaboração da proposta, as organizações proponentes busquem o apoio das prefeituras para a execução do Programa.

Vieira \& Del Grossi ${ }^{[8]}$ apontam a relevância do transporte dos produtos para a boa execução do PAA, sugerindo que a disponibilização de veículos pode ser uma das formas relevantes de apoio da prefeitura ao Programa. Os autores mencionam a importância da parceria com a prefeitura estudada, que viabilizou a aquisição de veículo para transporte dos produtos das propriedades rurais até as entidades consumidoras.

No caso estudado diferentes formas de organização da entrega foram identificadas, conforme a localização geográfica das entidades consumidoras. Nas escolas rurais, a entrega era realizada por grupos de agricultores da região, em datas previamente acordadas. Nas escolas urbanas, as entregas aconteciam sempre às terças-feiras, sob a responsabilidade da Cooperativa. Em ambas as situações, cabia aos agricultores levar os produtos até o local determinado pela Cooperativa ou até as escolas rurais. Observou-se ainda a existência de escolas rurais que não possuíam agricultores participantes do PAA no seu entorno, o que dificultou o fornecimento nessas unidades. Nesse caso, os produtos eram entregues no depósito de alimentos da Secretaria de Educação, que se responsabilizava pela distribuição, conforme a disponibilidade do caminhão da própria prefeitura. Cabe destacar que a prefeitura possuía apenas um caminhão com o qual eram realizadas inúmeras atividades, entre elas a entrega de alimentos para as unidades escolares. Quando ocorria 
algum imprevisto com o transporte dos produtos, os alimentos ficavam no depósito central da prefeitura, comprometendo o abastecimento e a qualidade dos alimentos.

$\mathrm{Na}$ entrega dos produtos, exige-se a apresentação de nota Fiscal de Venda; do "Termo de Recebimento e Aceitabilidade"; e de "Relatório de Entrega" [17]. No caso de entrega direta nas unidades escolares, estas ficam responsáveis por receber, conferir e aceitar os produtos. O recebimento dos alimentos era realizado por funcionários das escolas, na maioria dos casos por cozinheiros. A orientação repassada aos responsáveis pelo recebimento era de verificar os produtos no momento da entrega, informando a Secretaria de Educação a respeito das inconformidades identificadas e, se preciso, recusar o produto.

Vieira \& Del Grossi [8] chamam a atenção para a necessidade de complementação das normas do PAA no que se relaciona aos padrões de sanidade, embalagem e classificação para cada produto. Situação essa que pode ser agravada quando os encarregados de recebimentos não estão qualificados para exercer triagens e avaliações de tal natureza.

Em caso de produtos fora do padrão esperado, no que concerne ao tamanho, a entrega de um maior número de unidades estava sendo a estratégia utilizada pelos agricultores. Trata-se de situação complexa dada a heterogeneidade das embalagens utilizadas no acondicionamento dos produtos. As frutas e vegetais eram recebidas em caixas plásticas, redes ou sacolas plásticas. As decisões sobre normalização de quantidades tendiam a ser relativamente uniformes quando, na hora do recebimento, as caixas dos fornecedores eram substituídas por recipientes da própria unidade.

\section{CONCLUSÕES}

A operacionalização do Programa de Aquisição de Alimentos possui uma sistemática complexa, que envolve diversos setores governamentais e não governamentais. Evidencia-se a necessidade de articulação entre produção e consumo, com a finalidade de estruturar um cronograma de produção e entrega que vá ao encontro das necessidades dos produtores e atenda de forma regular as necessidades dos consumidores. Esse cronograma pode articular-se a programas de produção levando em conta a sazonalidade da oferta e o planejamento de cardápios, com resultados positivos para todos os envolvidos.

Nessa linha de pensamento, enfatiza-se a relevância dos conselhos municipais, diante da sua importância como espaço de participação e diálogo de diferentes segmentos, governamentais e não governamentais.

A complexidade de entrega dos produtos também foi demonstrada. $\mathrm{O}$ grande número de unidades distribuídas pelo território dificultou não apenas a distribuição dos produtos, como também o processo de recebimento. Nesse aspecto, é imperativa a construção de centrais de abastecimento que auxiliem no armazenamento e distribuição dos produtos.

A alimentação escolar é de fato um consumidor institucional potencial para os produtos locais. No entanto, para o sucesso de sua articulação com a agricultura familiar, perante o necessário fortalecimento desse segmento produtivo, é imprescindível o desenvolvimento de ações que auxiliem no fortalecimento das organizações dos agricultores, assim como o fomento a parcerias com a gestão municipal. A participação das prefeituras no apoio ao transporte e na organização cooperativada dos agricultores surge com destaque entre os fatores relevantes para o sucesso do Programa.

\section{REFERÊNCIAS}

[1] Brasil. Fundo Nacional de Desenvolvimento da Educação (FNDE). Lei no 11.947 de 16 de junho de 2009. Dispõe sobre o atendimento da alimentação escolar e do Programa Dinheiro Direto na Escola aos alunos da educação básica; altera as Leis no 10.880 , de 9 de junho de 2004, 11.273, de 6 de fevereiro de 2006, 11.507, de 20 de julho de 2007; revoga dispositivos da Medida Provisória n ${ }^{\circ}$ 2.178-36, de 24 de agosto de 2001, e a Lei no 8.913, de 12 de julho de 1994; e dá outras providências. Diário Oficial da União, Brasília, 16 jun. 2009. Seção 1, p. 2.

[2] Brasil. Casa Civil. Lei no 10.696, de 02 de julho de 2003. Dispõe sobre a repactuação e o alongamento de dívidas oriundas de operações de crédito rural, e dá outras providências. Diário Oficial da União, Brasília, 03 jul. 2003. Seção 1, p. 1.

[3] Brasil. Ministério do Desenvolvimento Social e Combate a Fome (MDS), Secretaria de Avaliação de Gestão da Informação (SAGI). Brasília: Secretaria de Avaliação de Gestão da Informação, 2011 [acesso em 24 ago 2013]. 
Disponível

em:

http://aplicacoes.mds.gov.br/sagi/paa/2011/visi paa geral Lpg principal.php?url=abertura

[4] Becker C, Sacco dos Anjos F. Segurança alimentar e desenvolvimento rural: limites e possibilidades do Programa de Aquisição de Alimentos da agricultura familiar, em municípios do sul gaúcho. Seg Alim Nutr. 2010;17(1):61-72.

[5] Delgado GC, Conceição JC, Oliveira JJ. Relatório de Avaliação do Programa de Aquisição de Alimentos da Agricultura Familiar (PAA). In: Botelho Filho FB. (Org.). Avaliação de políticas Públicas Rurais. Brasília: Universidade de Brasília, Centro de Estudos Avançados Multidisciplinares, Núcleo de estudos agrários; 2006.

[6] Müller AL, Fialho AV, Schneider S. A inovação institucional e a atuação dos atores locais na implementação do Programa de Aquisição de Alimentos no Rio Grande do Sul. Sociedade e Desenvolvimento Rural. 2007;1(1):1-21.

[7] Zimmermann SA, Ferreira AP. El programa de adquisición de alimentos de la agricultura familiar em Mirandiba-PE. In: Scotto G. (Org.). Aun hay tiempo para el sol: pobrezas rurales y programas sociales. Rio de Janeiro: Actionaid; 2008.

[8] Vieira DFA, Del Grossi ME. Influência do programa de aquisição de alimentos na comercialização dos produtos da agricultura familiar: o caso do município de Paracatu em Minas Gerais. Sociedade e Desenvolvimento Rural. 2010;4(2):21-48.

[9] Grisa C, Schmitt C, Mattei L, Maluf RS, Leite S. Contribuições do Programa de Aquisição de Alimentos à Segurança Alimentar e Nutricional e a criação de mercados para a agricultura familiar. Agriculturas. 2011;18(3):34-41.

[10] Soares P. Análise do Programa de Aquisição de Alimentos na Alimentação Escolar em um município de Santa Catarina [dissertação]. Florianópolis: Universidade Federal de Santa Catarina; 2011. 240 p.

[11] Doretto M, Michellon E. Avaliação dos impactos econômicos, socias e culturais do Programa de Aquisição de Alimentos no Paraná. Sociedade e Desenvolvimento Rural. 2007;1(1):107-38.

[12] Triches RM, Schneider S. Alimentação escolar e agricultura familiar: reconectando o consumo à produção. Saúde Soc. 2010;19(4):933-45.

[13] Cordeiro A. Oficina de documentação participativa do programa de aquisição de Alimentos da agricultura familiar PAA região sul. Relatório síntese. Curitiba: CONAB; 2006.
[14] Richardson RJ. Pesquisa Social: métodos e técnicas. São Paulo: Atlas; 1999.

[15] Brasil. Fundo Nacional de Desenvolvimento da Educação (FNDE). Resolução no 26, de 17 de junho de 2013. Dispõe sobre o atendimento da alimentação escolar aos alunos da educação básica no âmbito do Programa Nacional de Alimentação Escolar - PNAE. Diário Oficial da União, Brasilia, 18 jun. 2013. Seção 1, p. 7.

[16] Conselho Federal de Nutricionistas (CFN). Resolução no 465, de 23 de agosto de 2010. Dispõe sobre as atribuições do nutricionista, estabelece parâmetros numéricos mínimos de referência no âmbito do Programa de Alimentação Escolar (PAE) e dá outras providências. Diário Oficial da União, Brasilia, 25 ago. 2010. Seção 1, p. 118.

[17] Brasil. Companhia Nacional de Abastecimento (CONAB). Manual de Operações da CONAB (MOC). Título 30: Compra com Doação Simultânea (CDS). Brasília: Companhia Nacional de Abastecimento [acesso em 30 ago 2013]. Disponível em: http://www.conab.gov.br/conabweb/moc.php

[18] Brasil. Casa Civil. Decreto no 6.959, de 15 de setembro de 2009. Dá nova redação aos artigos 3으, 40 e 5o do decreto no 6.447 de 07 de maio de 2008, que regulamenta o artigo 19 da Lei no 10.696, de 02 de julho de 2003, que institui o Programa de Aquisição de Alimentos. Diário Oficial da União, Brasília, 16 set. 2009. Seção 1, p. 2.

[19] Brasil. Companhia Nacional de Abastecimento (CONAB). Cartilha de compra da Agricultura familiar com doação Simultânea - Cpr-doação. Brasilia: Companhia Nacional de Abastecimento [acesso em 10 fev 2013]. Disponível em: http://www.conab.gov.br/OlalaCMS/uploads/arquivos/63 dc985117c4d154786f6900d96af65c..pdf

[20] Botelho Filho FB, Carvalho AD, Schneider S, Fialho MA, Muller AL, Mattei L, et al. Estudo do impacto do PAA sobre os arranjos econômicos nas regiões nordeste e sul do Brasil. In: Paes-Souza R, Vaitsman J. Cadernos de estudo: desenvolvimento social em debate: síntese das pesquisas de avaliação de programas sociais do MDS. Brasília: Ministério do Desenvolvimento Social e Combate à Fome, Secretaria de Avaliação e Gestão da Informação; 2007. p. 65-67.

[21] Vieira DFA. Influência do Programa de Aquisição de Alimentos na Comercialização dos Produtos da Agricultura Familiar: o caso do município de Paracatu em Minas Gerais [dissertação]. Brasília: Universidade de Brasília; 2008. 149 p.

[22] Sparovek G, Teramoto E, Maule F, Klug ILF, Pereira JC, Smorigo J, et al. Estudo comparativo das diferentes 
modalidades do PAA - região nordeste. In: Paes-Souza R, Vaitsman J. Cadernos de estudo: desenvolvimento social em debate: síntese das pesquisas de avaliação de programas sociais do MDS. Brasilia: Ministério do Desenvolvimento Social e Combate à Fome, Secretaria de Avaliação e Gestão da Informação; 2007. p 62-64.

[23] Lima LS, Toledo JC. Gestão integrada da agricultura familiar - Módulo gestão da qualidade. São Carlos: Universidade Federal de São Carlos, Centro de Ciências Exatas e de Tecnologia. Departamento de Engenharia de Produção; 2004. 